\title{
Preoperative hidden renal dysfunction add an age dependent risk of progressive chronic kidney disease after cardiac surgery
}

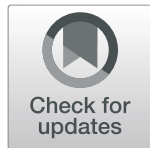

Jiarui $X u^{1,2,3,4 \dagger}$, Jiawei $Y u^{1,2,3,4 \dagger}$, Xialian $X u^{1,2,3,4}$, Bo Shen ${ }^{1,2,3,4}$, Yimei Wang ${ }^{1,2,3,4}$, Wuhua Jiang ${ }^{1,2,3,4}$, Wenlv Lv $v^{1,2,3,4}$, Yi Fang ${ }^{1,2,3,4,5}$, Zhe Luo ${ }^{6}$, Chunsheng Wang ${ }^{7}$, Jie Teng ${ }^{1,2,3,4,5,8^{*}}$ and Xiaoqiang Ding ${ }^{1,2,3,4,5,8^{*}}$

\begin{abstract}
Background: To study different value of estimated glomerular filtration rate with normal serum creatinine whether is a risk factor for hidden renal function of cardiac surgery outcomes.

Methods: A total of 1744 cardiac surgery patients with serum creatinine $\leq 1.2 \mathrm{mg} / \mathrm{dL}$ (female) $/ 1.5 \mathrm{mg} / \mathrm{dL}$ (male) were divided into 3 groups: estimated glomerular filtration rate $\geq 90 \mathrm{~mL} / \mathrm{min} / 1.73 \mathrm{~m}^{2}$ (no renal dysfunction, $n=829$ ), $60 \leq$ estimated glomerular filtration rate $<90 \mathrm{~mL} / \mathrm{min} / 1.73 \mathrm{~m}^{2}$ (hidden renal dysfunction, $n=857$ ), estimated glomerular filtration rate $<60 \mathrm{~mL} / \mathrm{min} / 1.73 \mathrm{~m}^{2}$ (known renal dysfunction, $n=58$ ) and followed up for 3 years. Multivariate regression analyses for risk factors of postoperative acute kidney injury.

Results: The proportion of preoperative hidden renal dysfunction was $67.1 \%$ among patients $\geq 65$ years old and $44.1 \%$ among patients $<65$ years old. Multivariate Cox regression analyses showed that for patients $<65$ years, known renal dysfunction was a risk factor for postoperative acute kidney injury $(P<0.01)$ and progressive chronic kidney disease $(P=0.018)$, while hidden renal dysfunction was a risk factor for progressive chronic kidney disease $(P=0.024)$. For patients $\geq 65$ years, only known renal dysfunction was a risk factors for 3 -year mortality $(P=0.022)$ and progressive chronic kidney disease $(P<0.01)$.

Conclusion: Hidden renal dysfunction was common in patients with normal serum creatinine for cardiac surgery, with a prevalence of $49.1 \%$. For patients $<65$ years old, hidden renal dysfunction was an independent risk factor for progressive chronic kidney disease.
\end{abstract}

Keywords: Cardiac surgery, Estimated glomerular filtration rate, Acute kidney injury, Progressive chronic kidney disease

\section{Background}

Preoperative renal dysfunction is a high risk factor for outcomes in cardiac surgery, not only for postoperative acute kidney injury (AKI), but also for in-hospital mortality and even long-term outcomes [1-3]. Renal dysfunction is mostly evaluated by serum creatinine ( $\mathrm{SCr}$ ), but scholars have noted that patients with normal $\mathrm{SCr}$ had estimated glomerular filtration rate (eGFR) values $<60 \mathrm{~mL} / \mathrm{min}$ and called it "occult renal

\footnotetext{
* Correspondence: teng.jie@zs-hospital.sh.cn; ding.xiaoqiang@zshospital.sh.cn

†Jiarui Xu and Jiawei Yu are first co-authors.

${ }^{1}$ Department of Nephrology, Zhongshan Hospital, Shanghai Medical College, Fudan University, No. 180 Fenglin Road, Shanghai 200032, China

Full list of author information is available at the end of the article
}

dysfunction", which significantly increased the risk of renal replacement therapy (RRT), inpatient death and prolonged hospitalization after coronary artery bypass grafting (CABG) surgery $[4,5]$. In the study of Volkmann et al., patients with plasma creatinine $(\mathrm{PCr}) \leq 1.5$ $\mathrm{mg} / \mathrm{dL}$ who underwent $\mathrm{CABG}$ were divided into 2 groups, estimated creatinine clearance $(\mathrm{eCrCl}) \geq 60 \mathrm{~mL} /$ min (normal renal function) or $\mathrm{eCrCl}<60 \mathrm{~mL} / \mathrm{min}$ (reduced renal function), respectively. The results showed that reduced renal function had a double risk of death, a longer total hospital stay and post-surgical hospital stay than those patients with normal renal function [6]. However, a considerable fraction of cardiac surgery patients may have normal SCr values and an eGFR under $90 \mathrm{~mL} /$

(c) The Author(s). 2019 Open Access This article is distributed under the terms of the Creative Commons Attribution 4.0 International License (http://creativecommons.org/licenses/by/4.0/), which permits unrestricted use, distribution, and 
$\mathrm{min} / 1.73 \mathrm{~m}^{2}$, but above $60 \mathrm{~mL} / \mathrm{min} / 1.73 \mathrm{~m}^{2}$, particularly since eGFR declines with age [7]. In the present retrospective, observational, single center study we analyzed whether patients with "normal" $\mathrm{SCr}$ and "hidden renal dysfunction" ( $60 \leq \mathrm{eGFR}<90 \mathrm{~mL} / \mathrm{min}$ ) have an enhanced risk of complications after cardiac surgery especially focusing on age-related eGFR decline.

\section{Methods}

\section{Patients}

In this retrospective, observational study, we collected data from patients who underwent cardiac surgery and with preoperative $\mathrm{SCr} \leq 1.2 \mathrm{mg} / \mathrm{dL}$ (female) $/ 1.5 \mathrm{mg} / \mathrm{dL}$ (male) in Shanghai Zhongshan Hospital between October 2012 and July 2013. Exclusion criteria were $<18$ years old; preoperative $\mathrm{SCr} \geq 1.2 \mathrm{mg} / \mathrm{dL}$ (female) / 1.5 $\mathrm{mg} / \mathrm{dL}$ (male) and received deep hypothermic circulatory arrest or heart transplantation. The Ethical Committee of Zhongshan Hospital affiliated to Fudan University approved the study (No. B2017-039) and written informed consent was obtained from all patients and our study was performed in accordance with the Declaration of Helsinki regarding the ethical principles for medical research involving human subjects.

\section{Definitions and groups}

Pre-operative hidden renal dysfunction was defined as $\mathrm{SCr} \leq 1.2 \mathrm{mg} / \mathrm{dL}$ (female) $/ 1.5 \mathrm{mg} / \mathrm{dL}$ (male) and $60 \leq$ eGFR $<90 \mathrm{~mL} / \mathrm{min} / 1.73 \mathrm{~m}^{2}$. AKI was defined according to the KDIGO 2012 criteria as the absolute value of the $\mathrm{SCr}$ increase $\geq 26.5 \mu \mathrm{mol} / \mathrm{L}$ within $48 \mathrm{~h}$ or an increase $>50 \%$ compared to the baseline values within 7 days, or a urine output $<0.5 \mathrm{~mL} / \mathrm{kg} / \mathrm{h} \geq 6 \mathrm{~h}$ [8].

Progressive chronic kidney disease (CKD) was defined as CKD stages $4-5$ (eGFR $\left.\leq 30 \mathrm{~mL} / \mathrm{min} / 1.73 \mathrm{~m}^{2}\right)$ including End-stage renal disease (ESRD) (receive maintenance renal replacement therapy or renal transplantation). CKD was diagnosed according to the Kidney Disease: Improving Global Outcomes (KDIGO) 2002 criteria [9]. All enrolled patients were divided into three groups: eGFR $\geq$ $90 \mathrm{~mL} / \mathrm{min} / 1.73 \mathrm{~m}^{2}$ (no renal dysfunction), $60 \leq \mathrm{eGFR}<$ $90 \mathrm{~mL} / \mathrm{min} / 1.73 \mathrm{~m}^{2}$ (hidden renal dysfunction) and eGFR $<60 \mathrm{~mL} / \mathrm{min} / 1.73 \mathrm{~m}^{2}$ (known renal dysfunction). Low cardiac output syndrome (LCOS) was diagnosed when patients had two or more of the following [10, 11]: (1) decreased systolic pressure $>20 \%$ of the basic preoperative value lasting $\geq 2 \mathrm{~h}$; (2) signs of impairment of body perfusion (cold extremities, lowered level of consciousness, or a combination of these signs) and lasting $\geq 2 \mathrm{~h}$; (3) need for at least three vasoactive drugs (dopamine, dobutamine, epinephrine or norepinephrine) or required an intra-aortic balloon pump (IABP). Intra-operative hypotension was defined as mean arterial pressure $<65 \mathrm{mmHg}$ and lasting $\geq 10 \mathrm{~min}$. High dose of vasoactive agents was defined as need of at least three vasoactive drugs, or the dose of norepinephrine or epinephrine more than $0.3 \mu \mathrm{g} / \mathrm{kg} / \mathrm{min}$. All the patients were followed up for 3 years through telephone, e-mail and hospital visits until October 2016. The primary endpoint was all causes of mortality and progressive CKD.

\section{Statistical analysis}

Statistical analysis was conducted with SPSS Statistics for Windows (Version 22.0, SPSS Inc., Chicago, US). Normally distributed data are presented as means \pm SD; groups were compared using two independent sample $t$ tests or ANOVA. Nonparametric data are expressed as medians $\left(P_{25}, P_{75}\right)$. The Wilcoxon test was used to assess two dependent variables, a non-parametric Mann-Whitney test for independent variables, and a chi-squared test for group comparisons. Multivariate Logistic regression analysis was used to investigate the influence of multiple factors of AKI incidence. Multivariate Cox regression analysis was used to investigate the effects of multiple factors on 3-year mortality and progressive CKD. A Pvalue $<0.05$ was considered to be statistically significant.

\section{Results}

\section{Baseline characteristics}

A total of 1744 patients were enrolled between October 2012 and July 2013. There were $47.53 \%(n=829)$ in the eGFR $\geq 90 \mathrm{~mL} / \mathrm{min} / 1.73 \mathrm{~m}^{2}$ group (no renal dysfunction), $49.14 \%(n=857)$ in the $60 \leq$ eGFR $<90 \mathrm{~mL} / \mathrm{min} /$ $1.73 \mathrm{~m}^{2}$ group (hidden renal dysfunction) and $3.33 \%$ $(n=58)$ in the eGFR $<60 \mathrm{~mL} / \mathrm{min} / 1.73 \mathrm{~m}^{2}$ group (known renal dysfunction) (Fig. 1).

Ages in hidden renal dysfunction group was significantly higher than in the no renal dysfunction group. The preoperative blood urea nitrogen (BUN) and $\mathrm{SCr}$ and uric acid in the hidden renal dysfunction group was significantly higher than in the no renal dysfunction group, but significantly lower than in the known renal dysfunction group. The proportion of proteinuria and renal ultrasound abnormal in hidden renal dysfunction group was significantly lower than in the known renal dysfunction group. The incidence of intra-operative hypotension in hidden renal dysfunction group was significantly lower than in the known renal dysfunction group (Table 1).

\section{AKI incidence and 3-year outcomes}

The AKI incidence of the overall patients was $34.29 \%$ $(n=598)$. There was no statistical difference of AKI incidence between the hidden renal dysfunction and no renal dysfunction group or known renal dysfunction group. The in-hospital mortality in the hidden renal dysfunction group was significantly higher than in the no renal dysfunction group. The 3-year mortality and 


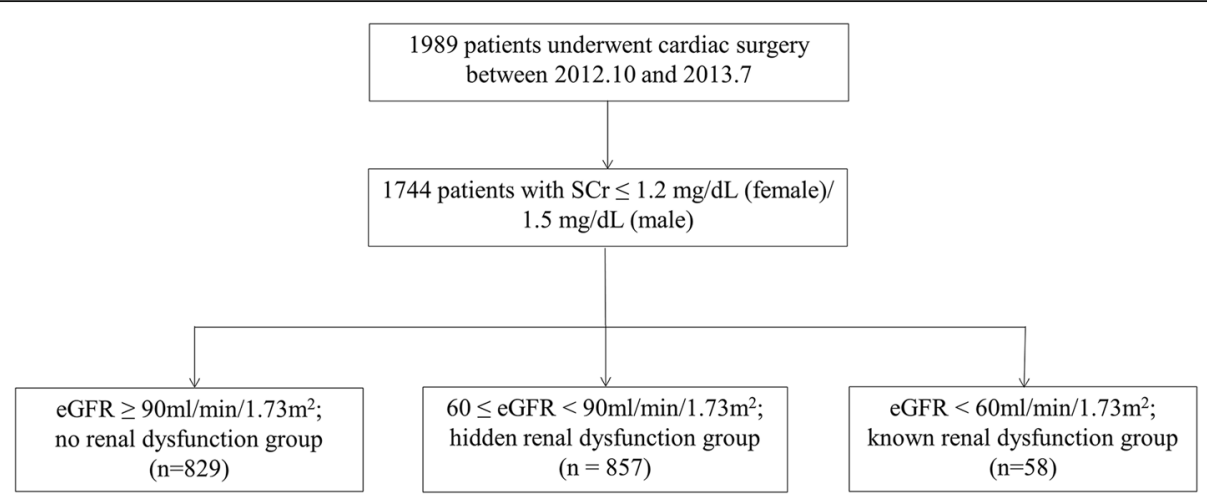

Fig. 1 Groupings of patients. Abbreviations: SCr, serum creatinine; eGFR, estimated glomerular filtration rate

Table 1 Baseline characteristics of patients with different degree of hidden renal dysfunction

\begin{tabular}{|c|c|c|c|c|}
\hline & $\begin{array}{l}\text { Total } \\
(n=1744)\end{array}$ & $\begin{array}{l}\text { eGFR } \geq 90 \\
\text { (no renal dysfunction) } \\
\text { ( } n=829)\end{array}$ & $\begin{array}{l}60 \leq e G F R<90 \\
\text { (hidden renal dysfunction) } \\
(n=857)\end{array}$ & $\begin{array}{l}\text { eGFR }<60 \\
\text { (known renal dysfunction) } \\
(n=58)\end{array}$ \\
\hline \multicolumn{5}{|l|}{ Pre-operation } \\
\hline Age & $53.00 \pm 14.00$ & $48 \pm 15$ & $58 \pm 12^{a}$ & $61 \pm 15$ \\
\hline Gender (male) & 1003 (57.51\%) & $485(58.50 \%)$ & $483(56.36 \%)$ & $35(60.34 \%)$ \\
\hline $\mathrm{BMI}\left(\mathrm{kg} / \mathrm{m}^{2}\right)$ & $22.8 \pm 3.5$ & $22.4 \pm 3.6$ & $23.1 \pm 3.4^{a}$ & $23.5 \pm 3.1$ \\
\hline Hypertension (n, \%) & $540(30.96 \%)$ & $223(26.90 \%)$ & $290(33.84 \%)^{b}$ & $27(46.55 \%)$ \\
\hline $\mathrm{DM}(\mathrm{n}, \%)$ & $200(11.47 \%)$ & 89 (10.74\%) & $100(11.67 \%)$ & 11 (18.97\%) \\
\hline NYHA > II (n, \%) & 1055 (60.49\%) & $445(53.68 \%)$ & $571(66.63 \%)$ & 39 (67.24\%) \\
\hline LVEF (\%) & $63.00 \pm 6.00$ & $68.00 \pm 6.00$ & $61.00 \pm 5.00^{a}$ & $60.00 \pm 5.00$ \\
\hline BUN (mmol/L) & $6.60 \pm 2.20$ & $5.90 \pm 1.60$ & $7.00 \pm 2.20 \mathrm{ab}$ & $9.60 \pm 3.40$ \\
\hline $\mathrm{SCr}(\mathrm{mg} / \mathrm{dL})$ & $0.87 \pm 0.22$ & $0.74 \pm 0.12$ & $0.96 \pm 0.15^{a b}$ & $1.09 \pm 0.12$ \\
\hline Uric acid $(\mu \mathrm{mol} / \mathrm{L})$ & $366.40 \pm 114.30$ & $334.10 \pm 98.80$ & $390.20 \pm 112.50 \mathrm{ab}$ & $457.20 \pm 126.70$ \\
\hline Proteinuria $(\mathrm{n}, \%)$ & $140(8.03 \%)$ & $65(7.84 \%)$ & $63(7.35 \%)^{b}$ & $12(20.69 \%)$ \\
\hline Urinalysis abnormal (n, \%) & 279 (16.00\%) & $132(15.92 \%)$ & $134(15.64 \%)$ & 13 (22.41\%) \\
\hline Renal ultrasound abnormal (n, \%) & $32(1.83 \%)$ & $9(1.09 \%)$ & $17(1.98 \%)^{b}$ & $6(10.34 \%)$ \\
\hline Hemoglobin $(\mathrm{g} / \mathrm{L})$ & $133.80 \pm 19.60$ & $134.30 \pm 20.40$ & $133.50 \pm 18.60$ & $130.40 \pm 21.50$ \\
\hline Platelet $\left(10^{9} / \mathrm{L}\right)$ & $181.00 \pm 61.20$ & $183.90 \pm 64.40$ & $178.10 \pm 57.40$ & $181.10 \pm 68.10$ \\
\hline \multicolumn{5}{|l|}{ Intra-operation } \\
\hline \multicolumn{5}{|l|}{ Types of surgery $(n, \%)$} \\
\hline - Valve & 903 (51.78\%) & $434(52.35 \%)$ & $445(51.93 \%)$ & $24(41.38 \%)$ \\
\hline$-C A B G / O P C A B$ & $309(17.72 \%)$ & $111(13.39 \%)$ & $185(21.59 \%)$ & $13(22.41 \%)$ \\
\hline - Aneurysm & $108(6.19 \%)$ & $57(6.88 \%)$ & $42(4.90 \%)$ & $9(15.52 \%)$ \\
\hline - Combined & 140 (8.03\%) & $58(7.00 \%)$ & $74(8.63 \%)$ & $8(13.79 \%)$ \\
\hline CPB duration (min) & $96.10 \pm 40.90$ & $94.40 \pm 39.70$ & $96.70 \pm 41.20^{b}$ & $112.70 \pm 50.10$ \\
\hline Aortic clamping time (min) & $47.40 \pm 42.30$ & $47.90 \pm 43.40$ & $46.90 \pm 41.30$ & $47.10 \pm 39.30$ \\
\hline Intra-operative hypotension ( $\mathrm{n}, \%)$ & $135(7.7 \%)$ & $58(7.0 \%)$ & $68(7.9 \%)^{b}$ & $9(15.5 \%)$ \\
\hline \multicolumn{5}{|l|}{ Post-operation } \\
\hline High dose of vasoactive agents ( $n, \%)$ & $271(15.5 \%)$ & $104(12.5 \%)$ & $153(17.9 \%)$ & $14(24.1 \%)$ \\
\hline $\operatorname{LCOS}(n, \%)$ & $118(6.8 \%)$ & $51(6.1 \%)$ & 59 (6.9\%) & 8 (13.9\%) \\
\hline
\end{tabular}

Abbreviations: eGFR estimated glomerular filtration rate, BMI body mass index, DM diabetes mellitus, NYHA New York Heart Association, LVEF left ventricular ejection fraction, $B U N$ blood urea nitrogen, $S C r$ serum creatinine, $C A B G$ coronary artery bypass grafting, $O P C A B$ off-pump coronary artery bypass, $C P B$ cardiopulmonary bypass, LCOS low cardiac output syndrome

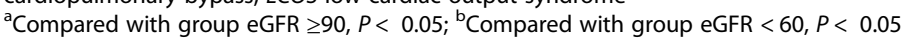


incidence of progressive CKD in the hidden renal dysfunction group was significantly higher than in the no renal dysfunction group, but significantly lower than in the known renal dysfunction group (Table 2).

\section{Age $<65$ years}

The AKI incidence was $31.19 \%(n=423)$ of patients under the age of 65 years. There was no statistical difference of AKI incidence between the hidden renal dysfunction and no renal dysfunction group or known renal dysfunction group. The 3-year mortality in the hidden renal dysfunction group was significantly lower than in the known renal dysfunction group. The in-hospital mortality and incidence of progressive CKD in hidden renal dysfunction was significantly higher than in no renal dysfunction group (Table 2).

\section{Age $\geq 65$ years}

The AKI incidence was $45.10 \%(n=175)$ of patients > 65 years old. There was no statistical difference of AKI incidence between the hidden renal dysfunction and no renal dysfunction group or known renal dysfunction group. The 3-year mortality in the hidden renal dysfunction group was significantly lower than in the known renal dysfunction group. There was no statistical difference of in-hospital mortality and incidence of progressive CKD between the hidden renal dysfunction and no renal dysfunction group or known renal dysfunction group (Table 2).

\section{Analysis of risk factors for postoperative AKI Age $<65$ years}

Multivariate Logistic regression analysis showed that age, gender (male), hypertension, aorta surgery, $\mathrm{CPB}$ time, LCOS, preoperative eGFR $<60 \mathrm{~mL} / \mathrm{min} / 1.73 \mathrm{~m}^{2}$ and intraoperative hypotension were independent risk factors of AKI after cardiac surgery (Table 3).

Multivariate Cox regression analysis showed that age, diabetes, postoperative AKI, length of ICU stay were independent risk factors of 3-year mortality (Table 4), and age, diabetes, $60 \leq \mathrm{eGFR}<90 \mathrm{~mL} / \mathrm{min} / 1.73 \mathrm{~m}^{2}$, eGFR < $60 \mathrm{~mL} / \mathrm{min} / 1.73 \mathrm{~m}^{2}$, postoperative AKI and length of ICU stay were independent risk factors of 3-year progressive CKD (Table 5).

\section{Age $\geq 65$ years}

Multivariate logistic regression analysis showed that age, gender (male), BMI, intraoperative hypotension and LCOS were independent risk factors of AKI after cardiac surgery (Table 3).

Multivariate Cox regression analysis showed that diabetes, length of ICU stay and eGFR $<60 \mathrm{~mL} / \mathrm{min} / 1.73$ $\mathrm{m}^{2}$ were risk factors for 3-year mortality (Table 4) and age, diabetes, eGFR $<60 \mathrm{~mL} / \mathrm{min} / 1.73 \mathrm{~m}^{2}$ and length of ICU stay were independent risk factors of 3-year progressive CKD (Table 5).

\section{Discussion}

It is commonly accepted that preoperative renal dysfunction is a risk factor for AKI, in-hospital mortality or even long-term outcomes after cardiac surgery [12]. Also

Table 2 AKI incidence and 3-year outcomes of patients with different degree of hidden renal dysfunction

\begin{tabular}{|c|c|c|c|c|}
\hline & & $\begin{array}{l}\text { eGFR } \geq 90 \\
\text { (no renal dysfunction) }\end{array}$ & $\begin{array}{l}60 \leq \mathrm{eGFR}<90 \\
\text { (hidden renal dysfunction) }\end{array}$ & $\begin{array}{l}\text { eGFR }<60 \\
\text { (known renal dysfunction) }\end{array}$ \\
\hline \multirow[t]{5}{*}{ All $(n=1744)$} & $\mathrm{N}$ & $829(47.53 \%)$ & 857 (49.14\%) & $58(3.33 \%)$ \\
\hline & AKI incidence & $271(32.69 \%)$ & $301(35.12 \%)$ & $26(44.83 \%)$ \\
\hline & In-hospital mortality & $19(2.29 \%)$ & $40(4.67 \%)^{\mathrm{a}}$ & $3(5.17 \%)$ \\
\hline & 3-year mortality & $61(7.36 \%)$ & $103(12.02 \%)^{a b}$ & $18(31.03 \%)$ \\
\hline & Progressive CKD incidence & $22(2.65 \%)$ & $52(6.07 \%)^{a b}$ & $9(15.52 \%)$ \\
\hline \multirow[t]{5}{*}{$<65$ years $(n=1356)$} & $N$ & 728 (53.69\%) & $597(44.03 \%)$ & 31 (2.29\%) \\
\hline & AKI incidence & $223(30.63 \%)$ & 187 (31.32\%) & $13(41.94 \%)$ \\
\hline & In-hospital mortality & 15 (2.06\%) & $28(4.69 \%)^{a}$ & $1(3.23 \%)$ \\
\hline & 3-year mortality & $36(4.95 \%)$ & $37(6.20 \%)^{b}$ & $5(16.13 \%)$ \\
\hline & Progressive CKD incidence & $18(2.47 \%)$ & $32(5.36 \%)^{a}$ & $4(12.90 \%)$ \\
\hline \multirow[t]{5}{*}{$\geq 65$ years $(n=388)$} & $\mathrm{N}$ & $101(26.03 \%)$ & $260(67.01 \%)$ & 27 (6.96\%) \\
\hline & AKI incidence & $48(47.52 \%)$ & $114(43.85 \%)$ & $13(48.15 \%)$ \\
\hline & In-hospital mortality & $4(3.96 \%)$ & $12(4.62 \%)$ & $2(7.41 \%)$ \\
\hline & 3-year mortality & $25(24.75 \%)$ & $66(25.38 \%)^{b}$ & $13(48.15 \%)$ \\
\hline & Progressive CKD incidence & $4(3.96 \%)$ & $20(7.69 \%)$ & $5(18.52 \%)$ \\
\hline
\end{tabular}


Table 3 Multivariate logistic regression analysis for the risk factors of postoperative AKI

\begin{tabular}{|c|c|c|c|c|c|c|}
\hline & Age $<65$ ye & & & Age $\geq$ & & \\
\hline & $\overline{\mathrm{OR}}$ & $95 \% \mathrm{Cl}$ & $P$ value & $\overline{\mathrm{OR}}$ & $95 \% \mathrm{Cl}$ & $P$-value \\
\hline Age & 1.030 & $1.012-1.078$ & $<0.01$ & 1.108 & $1.017-1.230$ & $<0.01$ \\
\hline Gender (male) & 2.451 & $1.890-3.378$ & $<0.01$ & 2.125 & $1.435-4.160$ & $<0.01$ \\
\hline BMI & & & & 1.078 & $1.011-1.146$ & 0.023 \\
\hline Hypertension & 1.389 & $1.028-1.785$ & 0.022 & & & \\
\hline Aorta surgery & 1.809 & $1.088-2.847$ & 0.013 & & & \\
\hline CPB time & 1.010 & $1.006-1.013$ & $<0.01$ & & & \\
\hline $\mathrm{eGFR} \geq 90 \mathrm{~mL} / \mathrm{min} / 1.73 \mathrm{~m}^{2}$ & Reference & - & - & & & \\
\hline $60 \leq \mathrm{eGFR}<90 \mathrm{~mL} / \mathrm{min} / 1.73 \mathrm{~m}^{2}$ & 1.729 & $0.764-3.021$ & 0.257 & & & \\
\hline $\mathrm{eGFR}<60 \mathrm{~mL} / \mathrm{min} / 1.73 \mathrm{~m}^{2}$ & 1.326 & $1.078-2.897$ & $<0.01$ & & & \\
\hline Intraoperative hypotension & 3.338 & $1.204-6.016$ & $<0.01$ & 2.013 & $1.034-3.145$ & $<0.01$ \\
\hline LCOS & 2.834 & $1.124-4.576$ & $<0.01$ & 2.126 & $1.018-3.896$ & $<0.01$ \\
\hline
\end{tabular}

Abbreviations: $B M I$ body mass index, CPB cardiopulmonary bypass, eGFR estimated glomerular filtration rate, LCOS low cardiac output syndrome

"occult renal insufficiency" defined as $\mathrm{SCr} \leq 100 \mu \mathrm{m}$ with $\mathrm{CrCl} \leq 60 \mathrm{~mL} / \mathrm{min}$ with an incidence rate of up to $13 \%$ has been shown to be associated with RRT [13], which is in accordance with our findings, that for patients with normal SCr under the age of 65 years, preoperative eGFR $<60 \mathrm{~mL} / \mathrm{min} / 1.73 \mathrm{~m}^{2}$ was an independent risk factor for AKI. However, interestingly for patients over the age of 65 years, preoperative eGFR $<60 \mathrm{ml} / \mathrm{min} / 1.73 \mathrm{~m}^{2}$ was not an independent risk factor for AKI in our study, but was still a risk factor for 3-year death and progressive CKD. The senescent kidney already shares morphological features of CKD [7], and the weighing of aging was heavier than eGFR in a multivariate regression analysis, which may explain the result.

However, most studies about preoperative renal dysfunction usually studied patients with eGFR $<60 \mathrm{~mL} /$ $\mathrm{min} / 1.73 \mathrm{~m}^{2}[6,14]$, but the risk of patients with mild decreased eGFR $\left(60 \sim 90 \mathrm{~mL} / \mathrm{min} / 1.73 \mathrm{~m}^{2}\right)$ and normal $\mathrm{SCr}$ is less evaluated. In the study by Howell et al. including 7621 consecutive patients who underwent CABG, valve surgery or combined procedures, eGFR $\geq$ $90 \mathrm{~mL} / \mathrm{min} / 1.73 \mathrm{~m}^{2}$ were considered normal renal function (reference group), eGFR $60-90 \mathrm{~mL} / \mathrm{min} / 1.73 \mathrm{~m}^{2}$ were mild renal dysfunction (group 2), eGFR 30-59 mL/ $\mathrm{min} / 1.73 \mathrm{~m}^{2}$ were moderate renal dysfunction (group 3) and eGFR $15-29 \mathrm{~mL} / \mathrm{min} / 1.73 \mathrm{~m}^{2}$ were severe renal dysfunction (group 4) and the results showed that eGFR of $60-90 \mathrm{~mL} / \mathrm{min} / 1.73 \mathrm{~m}^{2}$ (mild renal dysfunction) was an independent predictor of in-hospital and late mortality as well as cardiovascular complications [15], which is in line with our results, which revealed that for patients with normal $\mathrm{SCr}$ under the age of 65 years preoperative $60 \leq \mathrm{eGFR}<90 \mathrm{~mL} / \mathrm{min} / 1.73 \mathrm{~m}^{2}$ values became a risk factor for 3-year progressive CKD.

The mechanism why mild renal dysfunction contributes to poor outcomes is not clear. A possible explanation is that patients with impaired eGFR may have a more advanced cardiovascular disease and a reduced cardiac output before surgery. Along with aging, inflammatory mediators, endothelial dysfunction, left ventricular hypertrophy, all factors may contribute to the poor outcomes [16] and when eGFR values decreased to $60 \sim 90 \mathrm{~mL} / \mathrm{min} / 1.73 \mathrm{~m}^{2}$, it may be not obvious yet for the kidney to develop AKI, but the kidneys may be less able to recover from the injurious event of surgery.

Table 4 Multivariate cox regression analysis for the risk factors of 3-year mortality

\begin{tabular}{|c|c|c|c|c|c|c|}
\hline & \multicolumn{3}{|c|}{ Age $<65$ years } & \multicolumn{3}{|c|}{ Age $\geq 65$ years } \\
\hline & $\mathrm{OR}$ & $95 \% \mathrm{Cl}$ & $P$-value & $\overline{\mathrm{OR}}$ & $95 \% \mathrm{Cl}$ & $P$-value \\
\hline Age & 1.030 & $1.001-1.052$ & 0.044 & & & \\
\hline $\mathrm{DM}$ & 4.090 & $2.476-6.751$ & $<0.01$ & 3.670 & $2.475-5.455$ & $<0.01$ \\
\hline Postoperative AKI & 4.970 & $2.849-8.661$ & $<0.01$ & & & \\
\hline ICU stay & 1.002 & $1.001-1.004$ & $<0.01$ & 1.002 & $1.001-1.002$ & $<0.01$ \\
\hline $\mathrm{eGFR} \geq 90 \mathrm{~mL} / \mathrm{min} / 1.73 \mathrm{~m}^{2}$ & & & & Reference & - & - \\
\hline $60 \leq \mathrm{eGFR}<90 \mathrm{~mL} / \mathrm{min} / 1.73 \mathrm{~m}^{2}$ & & & & 1.160 & $0.726-1.843$ & 0.541 \\
\hline $\mathrm{eGFR}<60 \mathrm{~mL} / \mathrm{min} / 1.73 \mathrm{~m}^{2}$ & & & & 2.190 & $1.118-4.316$ & 0.022 \\
\hline
\end{tabular}

Abbreviations: AKI acute kidney injury, ICU intensive care unit, eGFR estimated glomerular filtration rate 
Table 5 Multivariate cox regression analysis for the risk factors of progressive CKD

\begin{tabular}{|c|c|c|c|c|c|c|}
\hline & \multicolumn{3}{|c|}{ Age $<65$ years } & \multicolumn{3}{|c|}{ Age $\geq 65$ years } \\
\hline & $\mathrm{OR}$ & $95 \% \mathrm{Cl}$ & $P$-value & $\mathrm{OR}$ & $95 \% \mathrm{Cl}$ & $P$-value \\
\hline Age & 1.040 & $1.010-1.064$ & 0.007 & 1.050 & $1.008-1.090$ & 0.018 \\
\hline DM & 3.310 & $2.020-5.435$ & $<0.01$ & 3.510 & $2.381-5.173$ & $<0.01$ \\
\hline $\mathrm{eGFR} \geq 90 \mathrm{~mL} / \mathrm{min} / 1.73 \mathrm{~m}^{2}$ & Reference & - & - & Reference & - & - \\
\hline $60 \leq \mathrm{eGFR}<90 \mathrm{~mL} / \mathrm{min} / 1.73 \mathrm{~m}^{2}$ & 1.690 & $1.071-2.669$ & 0.024 & 1.380 & $0.856-2.209$ & 0.187 \\
\hline $\mathrm{eGFR}<60 \mathrm{~mL} / \mathrm{min} / 1.73 \mathrm{~m}^{2}$ & 2.890 & $1.204-6.964$ & 0.018 & 2.870 & $1.472-5.580$ & $<0.01$ \\
\hline Postoperative AKI & 4.940 & $3.035-8.042$ & $<0.01$ & & & \\
\hline ICU stay & 1.002 & $1.001-1.004$ & $<0.01$ & 1.002 & $1.001-1.003$ & $<0.01$ \\
\hline
\end{tabular}

Abbreviations: eGFR estimated glomerular filtration rate, $A K I$ acute kidney injury, ICU intensive care unit, CKD chronic kidney disease

The cause of preoperative decreased eGFR is complicated and different for eGFR $60 \sim 90 \mathrm{~mL} / \mathrm{min} / 1.73 \mathrm{~m}^{2}$ and eGFR $<60 \mathrm{~mL} / \mathrm{min} / 1.73 \mathrm{~m}^{2}$ cases. For patients with eGFR $60 \sim 90 \mathrm{~mL} / \mathrm{min} / 1.73 \mathrm{~m}^{2}$, aging and increased BMI may be the main causes for decreased eGFR $[7,17,18]$. In patients over the age of 65 years, the proportion of hidden renal dysfunction was up to $67.0 \%$ in our study. It is considered that intimal thickening and decreased compliance of the renal vasculature contribute to observed $10 \%$ decreases in renal blood flow (RBF) per decade of life [19] and a decline in eGFR has been observed in patients without histological evidence of nephrosclerosis [20]. Also our results showed that though the rate of abnormalities in urinalysis and renal ultrasound was significantly higher in the eGFR $<60$ $\mathrm{mL} / \mathrm{min} / 1.73 \mathrm{~m}^{2}$ group, there was no statistical difference between $60 \leq \mathrm{eGFR}<90 \mathrm{~mL} / \mathrm{min} / 1.73 \mathrm{~m}^{2}$ and no renal dysfunction cases, which confirmed that most patients with eGFR $60-90 \mathrm{~mL} / \mathrm{min} / 1.73 \mathrm{~m}^{2}$ have no substantial damage. However, $44.0 \%$ of our patients $<65$ years old had hidden renal dysfunctions. Besides agedependent changes in kidney structure and function, increased exposure to comorbidities including cardiacrenal syndrome (type II, IV), hypertension, diabetes and nephrotoxic drugs may together increase the susceptibility of the kidney to develop AKI. The main cause may be the hemodynamic instability caused by cardiac-renal syndrome, since in our study, the proportion of New York Heart Association (NYHA) > II of the other three groups were significantly higher than in the no renal dysfunction group. Proportions of hypertension and diabetes also increased along with the decreased eGFR. Thus non-age dependent hidden renal dysfunction may be functional and reversible, and efforts could be made for better prevention of AKI.

Our study has some limitations. First, it was an observational and retrospective study in a single center, possibly not able to identify all potential confounding factors. Furthermore, mild renal dysfunction is always poorly defined. Our study used the cut-off of $\mathrm{SCr} \leq 1.2$ $\mathrm{mg} / \mathrm{dL}$ (female) $/ 1.5 \mathrm{mg} / \mathrm{dL}$ (male) which was arbitrarily chosen from the normal value of our hospital. We chose it because our aim was to raise the awareness of surgeons to concern about patients with conventionally regarded normal SCr but decreased eGFR,

\section{Conclusions}

Known renal dysfunction (eGFR $<60 \mathrm{~mL} / \mathrm{min} / 1.73 \mathrm{~m}^{2}$ ) was a significant risk factor of progressive CKD for both $\geq 65$ and $<65$ year old patients. However, hidden renal dysfunction $\left(60 \leq \mathrm{eGFR}<90 \mathrm{~mL} / \mathrm{min} / 1.73 \mathrm{~m}^{2}\right)$ correlated with progressive CKD only in $<65$ year old patients. Awareness should be raised for these patient group.

\section{Abbreviations}

AKl: Acute kidney injury; BMI: Body mass index; BUN: Blood urea nitrogen; CABG: Coronary artery bypass grafting; CKD: Chronic kidney disease; CPB: Cardiopulmonary bypass; DM: Diabetes mellitus; eCrCl: estimated creatinine clearance; eGFR: estimated glomerular filtration rate; ICU: Intensive care unit; LVEF: Left ventricular ejection fraction; NYHA: New York Heart Association; OPCAB: Off-pump coronary artery bypass; PCr: Plasma creatinine; RBF: Renal blood flow; RRT: Renal replacement therapy; SCr: Serum creatinine

\section{Acknowledgments}

None.

Authors' contributions

$J X, J Y, X X, B S, Y F, Z L, C W, X D$ and JT were responsible for the conception and design of the study. JX, JY, XX, BS, YW, WJ, WL and ZL were responsible for analysis of data; furthermore, JX, WJ and WL were in charge of statistical analysis. JX, JY and XX drafted the manuscript; YF, ZL, CW, XD and JT revised and commented the draft. All authors read and approved the final version of the manuscript

\section{Funding}

This work was supported by the Science and Technology Commission of Shanghai Municipality (Grant no. 17140902300), Shanghai Key Laboratory of Kidney and Blood Purification (Grant no. 14DZ2260200), Shanghai Shenkang Hospital Development Center New Frontier Technology Joint Project (Grant no. SHDC12018127) and the Xiamen Science and Technology Plan in 2018 (Grant no. 3502Z20184009). The funder had no role in the design of the study and collection, analysis, and interpretation of data, in writing the manuscript of the manuscript and in the decision to submit the article for publication.

\section{Availability of data and materials}

The datasets used and/or analysed during the current study are available from the corresponding author on reasonable request. 


\section{Ethics approval and consent to participate}

The Ethical Committee of Zhongshan Hospital affiliated to Fudan University approved the study (No. B2017-039) and written informed consent was obtained from all patients and our study was performed in accordance with the Declaration of Helsinki regarding the ethical principles for medical research involving human subjects.

\section{Consent for publication}

Not applicable.

\section{Competing interests}

The authors declare that they have no competing interests.

\section{Author details}

'Department of Nephrology, Zhongshan Hospital, Shanghai Medical College, Fudan University, No. 180 Fenglin Road, Shanghai 200032, China. ${ }^{2}$ Shanghai Medical Center of Kidney, No. 180 Fenglin Road, Shanghai 200032, China. ${ }^{3}$ Shanghai Institute for Kidney and Dialysis, No. 180 Fenglin Road, Shanghai 200032, China. ${ }^{4}$ Shanghai Key Laboratory of Kidney and Blood Purification, No. 180 Fenglin Road, Shanghai 200032, China. ${ }^{5}$ Hemodialysis Quality of Control Center of Shanghai, No. 180 Fenglin Road, Shanghai 200032, China. ${ }^{6}$ Department of Critical Care Medicine, Zhongshan Hospital, Shanghai Medical College, Fudan University, No. 180 Fenglin Road, Shanghai 200032, China. ${ }^{7}$ Department of Cardiovascular Surgery, Zhongshan Hospital, Shanghai Medical College, Fudan University, No. 180 Fenglin Road, Shanghai 200032, China. ${ }^{8}$ Department of Nephrology, Xiamen Branch, Zhongshan Hospital, Fudan University, No. 668 Jinhu Road, Xiamen 361015, Fujian, China.

\section{Received: 9 May 2019 Accepted: 15 August 2019}

Published online: 22 August 2019

\section{References}

1. Mao H, Katz N, Ariyanon W, Blanca-Martos L, Adybelli Z, Giuliani A, et al. Cardiac surgery-associated acute kidney injury. Cardiorenal Med. 2013;3(3):178-99.

2. Boyle JM, Moualla S, Arrigain S, Worley S, Bakri MH, Starling RC, et al. Risks and outcomes of acute kidney injury requiring dialysis after cardiac transplantation. Am J Kidney Dis. 2006;48(5):787-96.

3. Thakar CV, Arrigain S, Worley S, Yared JP, Paganini EP. A clinical score to predict acute renal failure after cardiac surgery. J Am Soc Nephrol. 2005; 16(1):162-8.

4. Miceli A, Bruno VD, Capoun R, Romeo F, Angelini GD, Caputo M. Occult renal dysfunction: a mortality and morbidity risk factor in coronary artery bypass grafting surgery. J Thorac Cardiovasc Surg. 2011;141(3):771-6.

5. Marui A, Okabayashi H, Komiya T, Tanaka S, Furukawa Y, Kita T, et al. Impact of occult renal impairment on early and late outcomes following coronary artery bypass grafting. Interact Cardiovasc Thorac Surg. 2013;17(4):638-43.

6. Volkmann MA, Behr PE, Burmeister JE, Consoni PR, Kalil RA, Prates PR, et al. Hidden renal dysfunction causes increased in-hospital mortality risk after coronary artery bypass graft surgery. Rev Bras Cir Cardiovasc. 2011;26(3):319-25.

7. Glassock RJ, Winearls C. Ageing and the glomerular filtration rate: truths and consequences. Trans Am Clin Climatol Assoc. 2009;120:419-28.

8. Group KDlgoKakiw. KDIGO clinical practice guideline for acute kidney injury. Kidney Int Suppl. 2012;2(1):1-138.

9. Foundation NK. KJDOQI clinical practice guidelines for chronic kidney disease: evaluation, classification, and stratification. Am J Kidney Dis. 2002; 39(2 Suppl 1):S1-266.

10. Maganti MD, Rao V, Borger MA, Ivanov J, David TE. Predictors of low cardiac output syndrome after isolated aortic valve surgery. Circulation. 2005;112(9 Suppl):1448-52.

11. Palomba H, de Castro I, Neto AL, Lage S, Yu L. Acute kidney injury prediction following elective cardiac surgery: AKICS score. Kidney Int. 2007; 72(5):624-31.

12. Jiang $W$, Teng J, Xu J, Shen B, Wang Y, Fang $Y$, et al. Dynamic predictive scores for cardiac surgery-associated acute kidney injury. J Am Heart Assoc. 2016:5(8):e003754

13. Wijeysundera DN, Karkouti K, Beattie WS, Rao V, Ivanov J. Improving the identification of patients at risk of postoperative renal failure after cardiac surgery. Anesthesiology. 2006;104(1):65-72.
14. Zakeri R, Freemantle N, Barnett V, Lipkin GW, Bonser RS, Graham TR, et al. Relation between mild renal dysfunction and outcomes after coronary artery bypass grafting. Circulation. 2005;112(9 Suppl):1270-5.

15. Howell NJ, Keogh BE, Bonser RS, Graham TR, Mascaro J, Rooney SJ, et al. Mild renal dysfunction predicts in-hospital mortality and post-discharge survival following cardiac surgery. Eur J Cardiothorac Surg. 2008;34(2):390-5.

16. Shlipak MG, Fried LF, Crump C, Bleyer AJ, Manolio TA, Tracy RP, et al. Elevations of inflammatory and procoagulant biomarkers in elderly persons with renal insufficiency. Circulation. 2003;107(1):87-92.

17. Kanasaki K, Kitada M, Koya D. Pathophysiology of the aging kidney and therapeutic interventions. Hypertens Res. 2012;35:1121.

18. Martensson J, Bellomo R. Prevention of renal dysfunction in postoperative elderly patients. Curr Opin Crit Care. 2014;20(4):451-9.

19. Musso CG, Oreopoulos DG. Aging and physiological changes of the kidneys including changes in glomerular filtration rate. Nephron Physiol. 2011; 119(Suppl 1):1-p5.

20. Rule AD, Amer H, Cornell LD, Taler SJ, Cosio FG, Kremers WK, et al. The association between age and nephrosclerosis on renal biopsy among healthy adults. Ann Intern Med. 2010;152(9):561-7.

\section{Publisher's Note}

Springer Nature remains neutral with regard to jurisdictional claims in published maps and institutional affiliations.
Ready to submit your research? Choose BMC and benefit from:

- fast, convenient online submission

- thorough peer review by experienced researchers in your field

- rapid publication on acceptance

- support for research data, including large and complex data types

- gold Open Access which fosters wider collaboration and increased citations

- maximum visibility for your research: over $100 \mathrm{M}$ website views per year

At BMC, research is always in progress.

Learn more biomedcentral.com/submissions 